\title{
Gene regulation in $\beta$-sitosterol-mediated stimulation of adipogenesis, glucose uptake, and lipid mobilization in rat primary adipocytes
}

\author{
Jen-Wai Chai $\cdot$ Siang-Ling Lim $\cdot$ M. S. Kanthimathi \\ Umah Rani Kuppusamy
}

Received: 8 June 2010/Accepted: 20 November 2010/Published online: 7 December 2010

(C) Springer-Verlag 2010

\begin{abstract}
The nutraceutical benefits of $\beta$-sitosterol (SIT) are well documented. The present study investigated the in vitro effects of SIT on adipogenesis, glucose transport, and lipid mobilization in rat adipocytes. Primary cultures of rat preadipocytes and differentiated adipocytes were used in this study. Glucose uptake was measured by the uptake of radio-labeled glucose. Adipogenesis and lipolysis were measured by oil-red-O and glycerol quantification methods, respectively. The expression of protein kinase B (Akt), glucose transporter 4 (GLUT4), hormone sensitive lipase (HSL), and phosphatidylinositol-3-kinase (PI3 K) genes in SIT-treated adipocytes were assessed by real-time reverse transcription polymerase chain reaction (RT-PCR). The data showed that SIT induced glucose uptake in adipocytes. It also stimulated adipogenesis in differentiating preadipocytes. Interestingly, although SIT displayed general insulin-mimetic activity by stimulating glucose uptake and adipogenesis, it also induced lipolysis in adipocytes. Furthermore, the SIT-induced lipolysis was not attenuated by insulin and co-incubation of SIT with epinephrine improved epinephrine-induced lipolysis. GLUT4 gene expression was highly down-regulated in SIT-treated adipocytes, compared to insulin-treated adipocytes, which was up-regulated. Insulin- and SIT-treated adipocytes showed similar levels of Akt, HSL, and PI3 K gene down-regulation. These observations suggest that the elevation of glucose uptake in SIT-treated adipocytes was unrelated to de novo synthesis of GLUT4 and the SIT-induced lipolysis is
\end{abstract}

J.-W. Chai · S.-L. Lim · M. S. Kanthimathi ·

U. R. Kuppusamy ( $\square)$

Department of Molecular Medicine, Faculty of Medicine,

University of Malaya, 50603 Kuala Lumpur, Malaysia

e-mail: umah@um.edu.my

URL: www.um.edu.my associated with the down-regulation of Akt and PI3K genes. The unique effects of SIT on the regulation of glucose uptake, adipogenesis, and lipolysis in adipocytes show that it has potential to be utilized in diabetes and weight management.

Keywords Beta-sitosterol - Adipocytes · Glucose uptake $\cdot$ Adipogenesis $\cdot$ Lipolysis

\section{Introduction}

Beta-sitosterol (SIT) is a naturally occurring plant sterol, ubiquitously found in many plants [31]. SIT has been reported to elicit a multitude of bioactivities, which include, antioxidant [40], anticancer [5], antiinflammatory [6], angiogenic [11, 28], chemopreventive [16], and immunomodulatory activities [8-10]. SIT is indicated for hypercholesterolemia [24] coronary heart disease [38], and benign prostate hyperplasia [39].

Phytosterol mixtures that contain SIT have been used as food additives in processed food for its nutraceutical benefits. For example, studies have shown that SIT-enriched margarine [36], butter [29], and orange juice [14] lower LDL cholesterol. In rats, it was estimated that four percent of SIT is absorbed into the body with a four-day dosing and showed longer retention time in the adrenal glands, ovaries, and intestinal mucosa, suggesting possible organ-specific actions [32].

Rats supplemented with oral SIT showed increased fasting insulin level, decreased fasting glucose level, improved oral glucose tolerance, and increased insulin release from isolated rat pancreatic islet cells $[17,18]$. SITtreated preadipocytes, 3T3-L1, showed inhibited growth, but stimulated triglyceride accumulation when co-incubated with oleic acid [4]. It was reported that plasma plant 
sterol concentrations were significantly lower in human diabetics compared to normal controls and serum insulin levels were inversely correlated with plasma plant sterol concentration in diabetics [34].

SIT regulation of the glucose and lipid metabolism in a muscle cell line was reported to be mediated by AMPactivated protein kinase [15]. However, the effect of SIT on the same metabolisms in adipocytes has not been delineated. In the present study, we investigated the effect of SIT on the glucose uptake, adipogenesis and lipolytic activity in rat adipocytes, as well as the gene expression of several insulin pathway regulatory genes in SIT-treated adipocytes.

\section{Materials and methods}

\section{Materials}

All tissue culture media, supplements, reagents, and chemicals were purchased from Sigma-Aldrich (St. Louis, USA) unless stated otherwise. SIT (85481) with purity of $\geq 70$ was obtained from Sigma-Aldrich (St. Louis, USA). Culture flasks were purchased from Nunc (Illinois, USA). Penicillin-streptomycin-glutamine solution and insulin were obtained from Invitrogen (California, USA). Glycerol, isobutylmethylxanthine (IBMX), dexamethasone, adenosine-5-triphosphate (ATP), and liquid scintillation cocktail (Cytoscint) were purchased from ICN (Ohio, USA). Type-II collagenase was purchased from Worthington (New Jersey, USA). Tritiated deoxyglucose (2-deoxy-D-[2,6- $\left.{ }^{3} \mathrm{H}\right]$ glucose) was purchased from Perkin Elmer (Massachusetts, USA). TaqMan ${ }^{\circledR}$ gene expression assay and master mixes were purchased from Applied Biosystems (California, USA).

\section{Primary culture and differentiation}

Primary preadipocytes were harvested according to a previously described method [22]. Briefly, preadipocytes were harvested from male rats (Ratus norvegicus; Spraguedawley strain) aged between 6 to 8 weeks. The rats were killed humanely by cervical dislocation. Intra-abdominal and epididymal fat pads were excised aseptically. The fat tissues were dissociated mechanically and digested enzymatically using Type-II collagenase for $1 \mathrm{~h}$ at $37^{\circ} \mathrm{C}$. Liberated preadipocytes were collected from the tissue digest by centrifugation at $100 \mathrm{~g}$ for $10 \mathrm{~min}$. Isolated preadipocytes from the pellet were cultured in $75 \mathrm{~cm}^{2}$ flasks with RPMI-1640 media supplemented with $10 \%$ fetal bovine serum (FBS), 2 mM L-glutamine, 100 units/ml sodium penicillin-G, $100 \mu \mathrm{g} / \mathrm{ml}$ streptomycin sulfate, and $2 \mathrm{mM}$ of amphotericin B. The culture medium was refreshed every
2-3 days until a confluent state was achieved. For some parts of this study, preadipocytes were differentiated to mature adipocytes using an appropriate cocktail of chemicals. To achieve this, preadipocytes were seeded into 12 -well plates and grown to confluence. They were differentiated in a differentiation media, which comprised of DMEM media supplemented with $2 \mathrm{mM}$ L-glutamine, 100 units/ml sodium penicillin-G, $100 \mu \mathrm{g} / \mathrm{ml}$ streptomycin sulfate, $2 \mathrm{mM}$ of amphotericin B, 10\% FBS, $17 \mu \mathrm{M}$ pantothenic acid, $0.5 \mathrm{mM}$ IBMX, $1 \mu \mathrm{M}$ dexamethasone, $10 \mu \mathrm{g} \mathrm{mL}^{-1}$ insulin, and $33 \mu \mathrm{M}$ biotin (Differentiation media-I, DM-I). On the third day of differentiation, both IBMX and dexamethasone were omitted from the differentiation media (Differentiation media-II, DM-II). Matured adipocytes of day-12 to day-15 were used for this study.

\section{Glucose uptake assay}

Glucose uptake activity in adipocytes was measured by using radio-labeled glucose [22]. Briefly, differentiated adipocytes in a 12-well plate were washed with PBS and serum-starved in serum-free DMEM media for $2 \mathrm{~h}$. Subsequently, the cells were incubated with various concentrations of SIT (dissolved in absolute ethanol and diluted with PBS to yield ethanol concentration of less than $1 \%$ $\mathrm{v} / \mathrm{v}$ ) for $30 \mathrm{~min}$ at $37^{\circ} \mathrm{C}$. Insulin was used as the positive control. The experiment was initiated by introducing radiolabeled reagent, which consisted of $100 \mathrm{mM}$ 2-deoxyglucose and $20 \mu \mathrm{Ci} / \mathrm{mL}$ 2-deoxy-D-[2,6- $\left.{ }^{3} \mathrm{H}\right]$ glucose in PBS. The mixture was incubated for $10 \mathrm{~min}$ at $37^{\circ} \mathrm{C}$. Subsequently, the cells were washed twice with ice-cold PBS before they were lysed with scintillation cocktail. Radioactivity emitted by the radio-labeled glucose taken up by the adipocytes was measured with a scintillation counter (Packard, Tri-carb).

Oil-red-O staining

Adipogenic activity was measured using the oil-red-O staining method [2, 22]. SIT was used in substitution of insulin in the DM-II. On day-12 of the differentiation, the cells were washed with PBS and fixed with $0.5 \%$ formaldehyde prior to oil-red-O staining. The adipocytes were stained for $1 \mathrm{~h}$ at room temperature and washed with PBS. The stained lipids present in the mature adipocytes were solubilized with isopropanol and measured spectrophotometrically at $510 \mathrm{~nm}$.

Glycerol quantification assay

Lipolytic activity was measured by glycerol quantification method [22, 37]. Glycerol released from hydrolyzed triacylglycerols was quantified. Differentiated, mature 
adipocytes were serum starved 1 day prior to the experiment. The cells were treated with test compounds dissolved in PBS for $5 \mathrm{~h}$. Thereafter, $100 \mu \mathrm{l}$ of the buffer containing the released glycerol was mixed with $200 \mu \mathrm{l}$ of glycerol quantification reagent, which comprised of $75 \mathrm{mM}$ ATP, $3.75 \mathrm{mM}$ magnesium salt, $0.188 \mathrm{mM}$ 4-aminoantipyrine, $2.11 \mathrm{mM}$ sodium-N-ethyl-N-(3-sulfopropyl)-m-aniside (ESPA), 1,875 U/L glycerol kinase (microbial), 3,750 U/L glycerol phosphate oxidase (microbial), and 3,750 U/L peroxidase (horseradish) in TRIS-buffered saline (pH 7.0). The mixture was incubated for $15 \mathrm{~min}$ at $37^{\circ} \mathrm{C}$. The optical density of the quinoneimine chromogen was quantified spectrophotometrically at $540 \mathrm{~nm}$.

Quantitative real-time reverse transcriptase-polymerase chain reaction

Total RNA from cultured adipocytes were isolated with a commercialized spin cartridge kit (Invitrogen; $\mathrm{P} / \mathrm{N}$ : 12183-018) according to the manufacturer's protocol. First-strand cDNA was synthesized immediately after the total RNA was extracted by using a cDNA synthesis kit (Applied Biosystems; P/N: 4368814). Gene expression levels were analyzed by quantitative real-time reverse transcriptase-polymerase chain reaction (RT-PCR) using StepOnePlus real-time PCR system (Applied Biosystems). The assay protocol numbers for the genes investigated are depicted in Table 1. The mRNA levels of all genes were normalized using $18 \mathrm{~S}$ rRNA. Relative gene expression was determined by the $\Delta \Delta \mathrm{C}_{\mathrm{T}}$ method [23].

\section{Statistical analysis}

Statistical analysis was performed using the GraphPad Prism version 5.02 for Windows (GraphPad Software, San Diego California USA, www.graphpad.com). Data were expressed as mean \pm standard deviation, unless stated otherwise. Analysis of variance was performed using standard Student's- $t$ test and ANOVA.

\section{Results}

Effect of SIT on glucose uptake in adipocytes

To determine the glucose uptake activity, the radioactivity in adipocytes incubated with tritiated glucose was measured. Insulin was used as the positive control. The results showed that insulin stimulated glucose uptake in adipocytes over a dose range from 1 to $10,000 \mu \mathrm{M}$ (Fig. 1a). SIT dose-dependently stimulated glucose uptake in adipocytes at concentrations ranging from 0.1 to $100 \mu \mathrm{M}$ (Fig. 1b). There was no improvement in glucose uptake between $100 \mu \mathrm{M}$ and $1,000 \mu \mathrm{M}$ SIT-treated adipocytes. Insulin's effect on glucose uptake generally showed batch to batch variation between experiments. Experiments conducted using primary preadipocytes isolated from different rats showed variation in the extent of differentiation, as can be seen in Fig. 1a, b at $100 \mu \mathrm{M}$ insulin induced differentiation. Therefore, insulin was included as a positive control in each experiment.

\section{Effect of SIT on adipogenesis}

To assess the effect of SIT on the differentiation of preadipocytes to adipocytes (i.e., adipogenesis), the insulin in DM-II was substituted with SIT. Adipogenesis was measured by assessing the lipid content of differentiating preadipocytes. Insulin was used as the standard reference for this experiment. Insulin concentrations from 0.1 to $100 \mu \mathrm{M}$ stimulated adipogenesis in preadipocytes in a dose-dependent manner (Fig. 2a). The adipogenic effect of insulin at 100 and $1,000 \mu \mathrm{M}$ did not show significant difference. Figure $2 \mathrm{~b}$ shows that SIT stimulated adipogenesis in a dose-dependent manner within concentrations ranging from 0.1 to $1,000 \mu \mathrm{M}$.

\section{Effect of SIT on lipolysis in adipocytes}

To examine the lipolytic activity of SIT, the amount of glycerol released from treated adipocytes was measured. Figure $3 \mathrm{a}, \mathrm{b}$ showed that epinephrine stimulated lipolysis,

Table 1 Genes investigated

\begin{tabular}{lll}
\hline Gene name and abbreviation & Assay ID & Accession number \\
\hline Protein kinase B (Akt) & Rn00583646_m1 & NM_033230.1 \\
Glucose transporter 4 (GLUT4) & Rn00562597_m1 & NM_012751.1 \\
Hormone sensitive lipase (HSL) & Rn00689222_m1 & NM_012859.1 \\
Phosphatidylinositol-3-kinase (PI3 K) & Rn00564547_m1 & NM_013005.1 \\
\hline
\end{tabular}

General abbreviation of genes selected for this study and corresponding assay ID and accession information are available on Applied Biosystems website (www.appliedbiosystems.com). Assay ID refers to the "Applied Biosystems Gene Expression Assays" inventoried kit with proprietary primer and TaqMan ${ }^{\circledR}$ probe mix. Assay ID with "Rn" prefix denotes "Rattus norvegicus". All gene expression assay kits used were FAM/MGB probed. Eukaryotic $18 \mathrm{~S}$ rRNA was used as the endogenous control 
Fig. 1 Effect of a insulin and b SIT on glucose uptake in adipocytes. Uptake of radiolabeled glucose in adipocytes was measured by scintillation counting. The relative percentage of glucose uptake was calculated by comparing experimental values with the normal control (vehicle). Insulin was used as the positive control. Panel (a) and (b) are of two separate experiments performed in quadruplicates
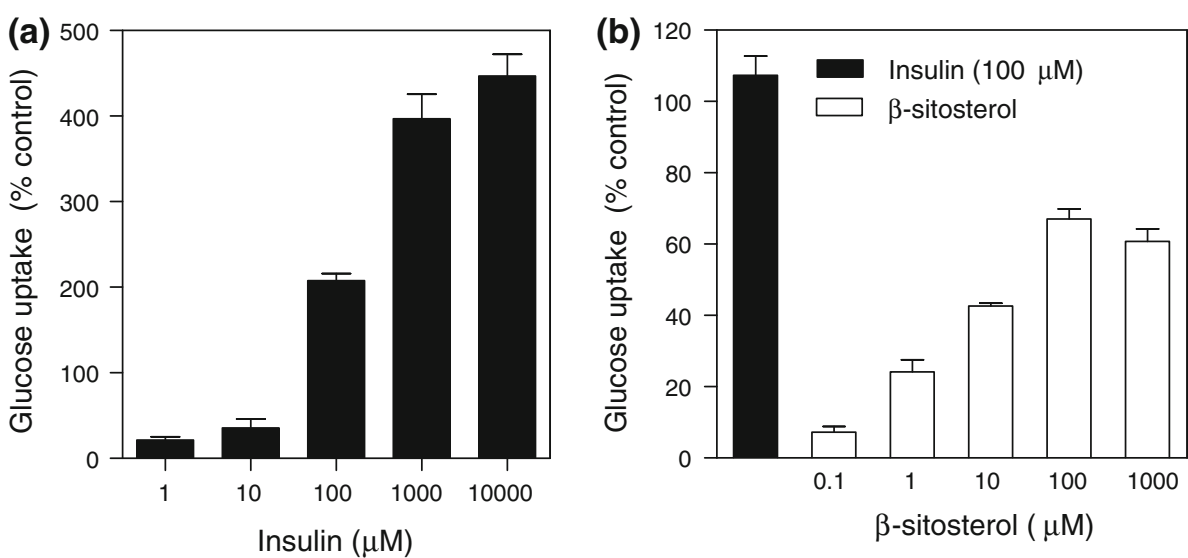

Fig. 2 Effect of a insulin and b SIT on adipogenesis in preadipocytes. Adipogenesis was measured by assessing the lipid content of differentiating preadipocytes. The relative percentage of adipogenesis was calculated by comparing the experimental values with the normal control (vehicle). Insulin was used as the positive control. Panel (a) and (b) are of two separate experiments performed in quadruplicates

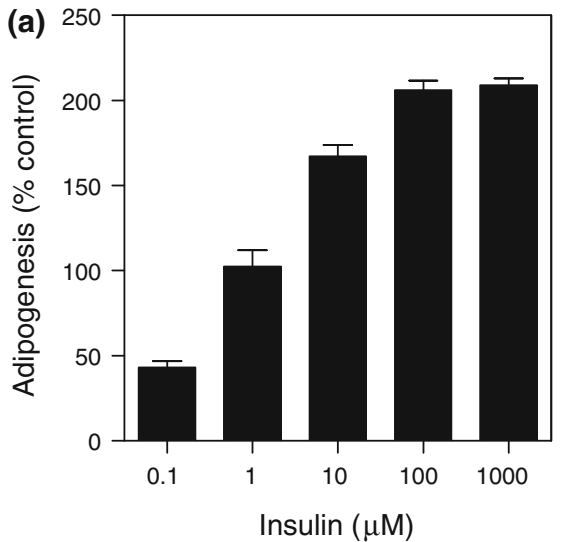

whereas insulin inhibited lipolysis in adipocytes. Furthermore, it was also demonstrated that insulin attenuated epinephrine-induced lipolysis (Fig. 3c). Adipocytes treated with SIT showed induced lipolytic activity, which behaved dose-dependently with concentrations from 0.1 to $100 \mu \mathrm{M}$ and plateaued from 100 to $1,000 \mu \mathrm{M}$ (Fig. 3c). Unlike epinephrine, co-incubation of SIT with insulin did not attenuate SIT-induced lipolysis. In addition, co-incubation of epinephrine with SIT showed increased lipolytic activity compared to epinephrine alone (Fig. 3c).

Effect of SIT on mRNA expression in adipocytes

To ascertain whether SIT elicited any effect on the expression of insulin pathway regulatory genes, the mRNA levels of these genes (Table 1) in SIT-treated adipocytes were examined. Among the four genes investigated, GLUT4 gene expression showed significant difference among the treated samples. Adipocytes treated with insulin $(10 \mu \mathrm{g} / \mathrm{ml})$ showed significant up-regulation of GLUT4 gene expression by 2.59 -fold $(P<0.001)$ compared to experimental blank (Fig. 4). In contrast, SIT- $(10 \mu \mathrm{M})$ treated adipocytes showed significant down-regulation of GLUT4 gene expression by -15.51 -fold $(P<0.001)$.
Figure 4 also showed that there was a significant $(P<0.001)$ down-regulation of Akt, HSL, and PI3 K gene expression in insulin- and SIT-treated adipocytes.

\section{Discussion}

Insulin binds to the insulin receptor leading to the autophosphorylation of insulin receptor substrates (IRS) mediated by tyrosine kinase activity. This is followed by a phosphorylation cascade involving phosphoinositide-3kinase (PI3 K), phosphoinositide-dependant kinase-1 (PDK-1), and the downstream effector Akt/PKB (Protein kinase $\mathrm{B})$, which results in the translocation of glucose transporter-4 (GLUT4) from the cytoplasmic vesicles to the cell membrane, thus facilitating the transport of glucose into the cell [7]. Lipogenesis and lipolysis are governed, in most part, by the insulin and epinephrine pathways. Epinephrine action is mediated by the $\beta$-adrenergic receptors, activating the adenylyl cyclase signaling pathway to produce cAMP, triggering protein kinase A (PKA), which in turn activates the hormone sensitive lipases by phosphorylation. The concentration of cellular cAMP is regulated by the insulin pathway. 
Fig. 3 Effect of a epinephrine, b insulin and c SIT on lipolysis in adipocytes. Lipolysis was measured by assessing the amount of glycerol released from adipocytes. The relative percentage of lipolysis was calculated by comparing the experimental values with the normal control (vehicle). Epinephrine and insulin were used as the positive and negative controls, respectively. Each panel represents separate experiments performed in quadruplicates. In panel (c), statistical difference was compared using one-way ANOVA; $a$ denotes $P<0.001$ versus epinephrine, $b$ denotes $P<0.001$ versus SIT, $c$ denotes $P<0.01$ versus SIT and $d$ indicates $P<0.001$ versus epinephrine
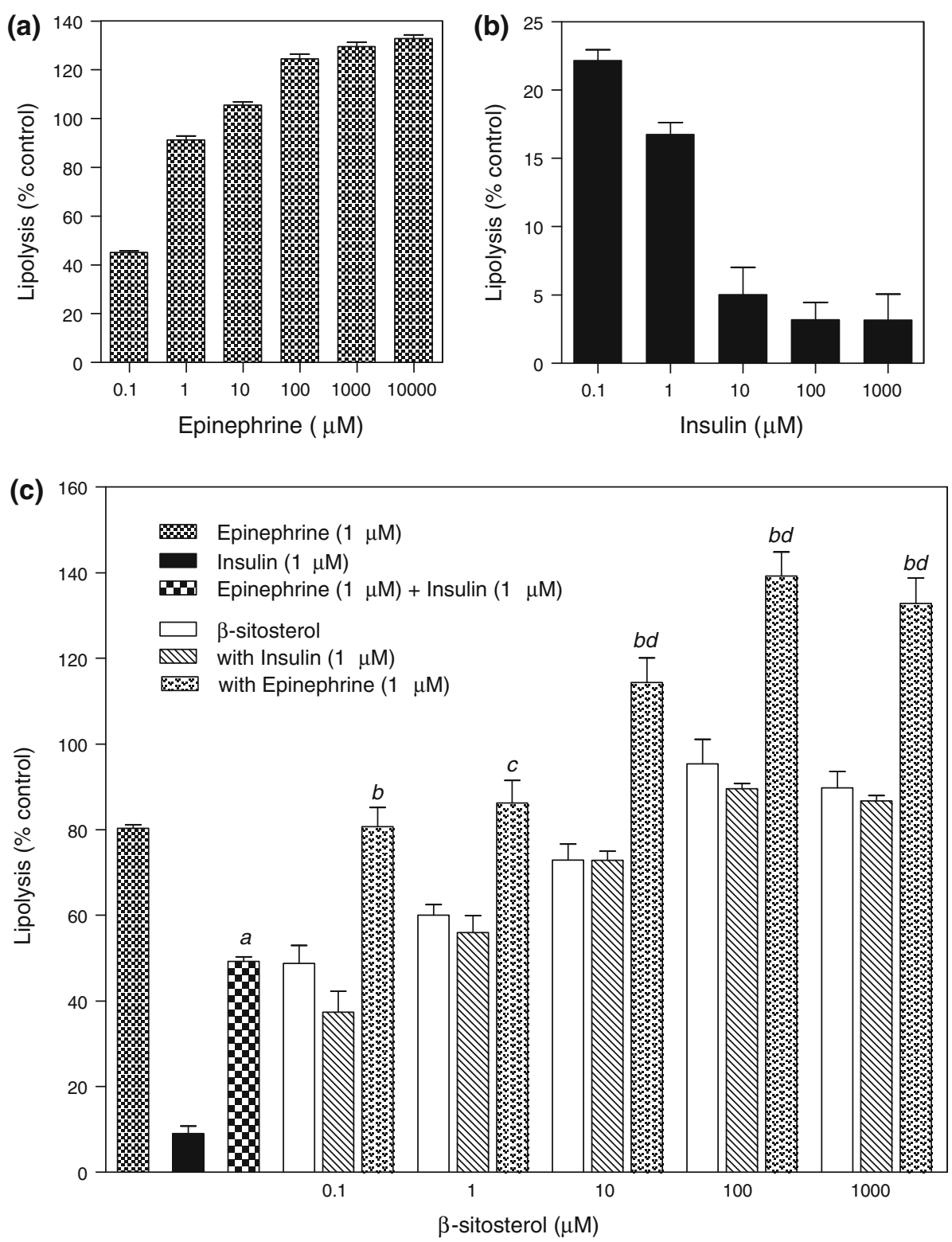

Activation of phosphodiesterase (PDE) via the phosphorylation cascade initiated by insulin reduces the effect of epinephrine by breaking the cAMP's phosphodiester bond [33].

Primary rat preadipocytes and subsequently differentiated adipocytes are accepted models of study for diabetes and obesity [22]. To elucidate the action of SIT on glucose and fat metabolism, the in vitro metabolic responses of primary preadipocytes and differentiated adipocytes treated with SIT were investigated. It has been demonstrated in normal and hyperglycemic rats that oral supplementation of SIT increased fasting plasma insulin levels with corresponding decreased fasting glucose levels [17]. This was attributed to increased secretion of insulin [17, 18]. In this study, the results show that SIT induced glucose uptake in rat adipocytes (Fig. 1b). This suggests that SIT has insulinlike activity besides being an insulin secretagogue. Similar to adipocytes, muscle cells are equally important in maintaining homeostasis of blood glucose levels [25]. In a recent report, Hwang et al. [15] showed that SIT induced glucose uptake in a muscle cell line. It was reported that 3T3-L1 cells, a mice-derived preadipocyte cell line, showed inhibited growth and increased triglyceride accumulation when treated with SIT [4]. Corresponding to their report, the data presented here shows that SIT induces adipogenesis by increasing the lipid content in differentiating rat preadipocytes (Fig. 2b). The inhibited growth observed by Awad et al. [4] in SIT-treated 3T3-L1 cells may be associated with growth arrest usually observed in the preadipocytes differentiation [13]. 


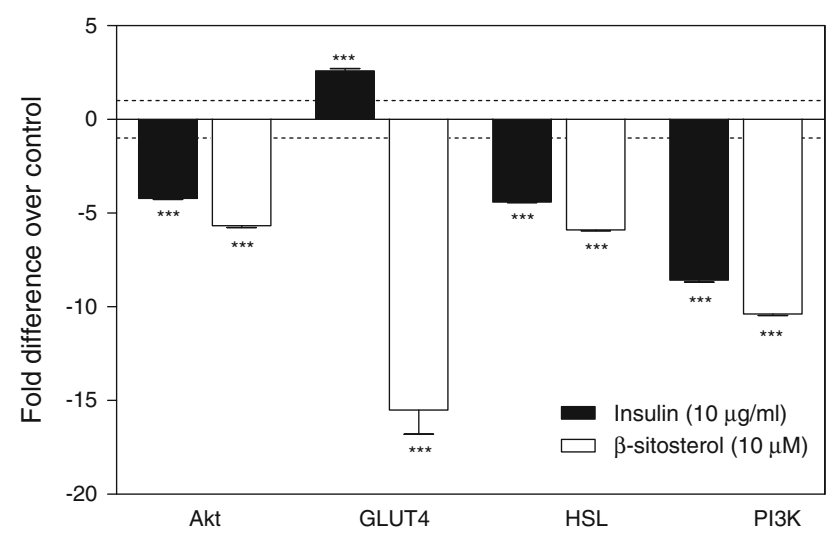

Fig. 4 Gene expression analysis. The results are expressed as-fold difference over carrier control. Eukaryotic $18 \mathrm{~S}$ rRNA was used as the endogenous control. Fold difference inferior to 0 were expressed as negative numbers (e.g., a-fold difference of 0.50 is expressed as -2.00 ). Results presented as mean \pm standard deviation. Variation between +1 and -1 , corresponds to no change, are represented by the dotted lines. Statistical significance was calculated based on the mean $\Delta \mathrm{C}_{\mathrm{T}}$ values by Student's- $t$ test; **denotes $P<0.01$ and $* * *$ denotes $P<0.001$ versus carrier control

Besides affecting glucose transport, SIT also has been reported to reduce triglyceride content in myotube cells mediated by AMP-protein activated kinase (AMPK) activation [15]. The data presented here also show that SIT induced lipolysis in adipocytes indicated by the increased release of glycerol in SIT-treated adipocytes (Fig. 3c). The data also showed that there is a possible of interaction between the lipolytic effects of SIT with the epinephrineinduced lipolysis. Adipocytes co-incubated with SIT and epinephrine showed significant increase in glycerol release compared to epinephrine-treated cells (Fig. 3c). Epinephrine induces lipolysis in adipocytes, whereas insulin inhibits lipolysis. Ex vivo experiments conducted on rat adipocytes showed that insulin could attenuate epinephrine-induced lipolysis [30]. This observation concurs with our results. Figure $3 \mathrm{c}$ shows that co-incubation of insulin significantly $(P<0.001)$ reduced the lipolytic activity of epinephrine. However, insulin could not attenuate the lipolysis induced by SIT (Fig. 3c). This observation suggests that the lipolytic effect of SIT is not affected by the antilipolytic effects of insulin. It was reported that genistein enhanced basal lipolysis in isolated adipocytes [19] and antagonized the antilipolytic action of insulin in isolated rat adipocytes by increasing cellular cAMP and activating protein kinase A [35]. Therefore, SIT effects observed here may be similar to that of genistein, as they both demonstrated lipolytic activity, which is accompanied by impairment of the antilipolytic activity of insulin.

To elucidate the molecular events behind the effects of SIT on adipocytes, the expression level of several key transcriptional genes in the insulin and epinephrine pathways was examined (Table 1). For this experiment (Fig. 4), $10 \mu \mathrm{M}$ of SIT was used. This concentration was chosen as it represents the effective concentration at 50\% $\left(E_{50}\right)$ for the various biochemical parameters measured in this study. The modulation of these genes in insulin-treated rat adipocytes in this study was compared to a previous study performed on 3T3-L1 cells [21] and was found to be modulated in a similar pattern. Compared to untreated rat adipocytes, insulin treatment up-regulated GLUT4 gene expression and down-regulated Akt, HSL and PI3 K gene expression (Fig. 4). Collectively, the data presented here indicate that both mice- and rat-derived adipocytes display similar biochemical and molecular responses when treated with insulin. Interestingly, increased glucose uptake activity in SIT-treated adipocytes (Fig. 1b) is not accompanied with up-regulation of GLUT4 gene expression. Instead, SIT down-regulated the expression of the GLUT4 gene (Fig. 4). This suggests that the increased glucose uptake activity in SIT-treated adipocytes is likely to be mediated by the translocation of preexisting GLUT4 and not attributed to de novo translation of GLUT4. Whereas the down-regulation of Akt, HSL, and PI3 K gene expression (Fig. 4) in both insulin- and SIT-treated adipocytes suggest that their role in regulating glucose uptake is probably regulated at the post-translational level.

Activation of the PI3 K/Akt protein cassette stimulates the translocation of GLUT4 and increases glucose uptake [1]. SIT treatment has been reported to cause mixed reactions to PI3 K/Akt signaling in different cancer cell lines; in murine fibrosarcoma cells (MCA-102), SIT treatment inactivated PI3 K/Akt signaling [27], whereas in human leukemic cell line U937, SIT induced PI3 K/Akt phosphorylation [26]. PI3 $\mathrm{K}$ regulates the activation of the extracellular signal-regulated kinase 1 and 2 (ERK1/2) and the PPAR $\gamma$ pathway, which leads to the accumulation of lipids induced by a hyperglycemic condition [12]. PI3 K also plays an important role in adipogenesis and the preadipocytes differentiation. Inhibition of PI3 $\mathrm{K}$ in human adipocytes significantly reduces triacylglycerol accumulation and fatty acid synthase protein expression [3]. In addition, 3T3-L1 cells treated with PI3 K inhibitor showed decreased lipid accumulation [20]. Therefore, the lipolytic activity of SIT and its ability to improve epinephrineinduced lipolysis (Fig. 3c) may be associated with the down-regulation of Akt and PI3 K gene expression in SITtreated adipocytes (Fig. 4). In conclusion, the present study demonstrated that SIT treatment could affect the glucose transport and lipid mobilization in adipocytes. These effects are mediated by the activation and regulation of GLUT4 and PI3 K/Akt.

Acknowledgments We thank Prof. Rais Mustafa for his advice and assistance on the glucose uptake assay. This study was made possible 
by the Research University Grant scheme, University of Malaya (Grant No: FS016/2007A).

\section{References}

1. Abe D, Saito T, Sekiya K (2006) Sennidin stimulates glucose incorporation in rat adipocytes. Life Sci 79:1027-1033. doi: 10.1016/j.lfs.2006.03.007

2. Akerblad P, Lind U, Liberg D, Bamberg K, Sigvardsson M (2002) Early B-cell factor (O/E-1) is a promoter of adipogenesis and involved in control of genes important for terminal adipocyte differentiation. Mol Cell Biol 22:8015-8025. doi:10.1128/MCB. 22.22.8015-8025.2002

3. Aubin D, Gagnon A, Sorisky A (2005) Phosphoinositide 3-kinase is required for human adipocyte differentiation in culture. Int $\mathrm{J}$ Obes (Lond) 29:1006-1009. doi:10.1038/sj.ijo.0802961

4. Awad AB, Begdache LA, Fink CS (2000) Effect of sterols and fatty acids on growth and triglyceride accumulation in 3T3-L1 cells. J Nutr Biochem 11:153-158. doi:10.1016/S0955-2863(99) 00087-X

5. Awad AB, Chinnam M, Fink CS, Bradford PG (2007) BetaSitosterol activates Fas signaling in human breast cancer cells. Phytomedicine 14:747-754. doi:10.1016/j.phymed.2007.01.003

6. Backhouse N, Rosales L, Apablaza C, Goity L, Erazo S, Negrete R, Theodoluz C, Rodriguez J, Delporte C (2008) Analgesic, antiinflammatory and antioxidant properties of Buddleja globosa, Buddlejaceae. J Ethnopharmacol 116:263-269. doi:10.1016/j.jep. 2007.11.025

7. Bevan P (2001) Insulin signalling. J Cell Sci 114:1429-1430. PMID: 11282018

8. Bouic PJ (2001) The role of phytosterols and phytosterolins in immune modulation: a review of the past 10 years. Curr Opin Clin Nutr Metab Care 4:471-475. PMID:11706278

9. Bouic PJ, Clark A, Lamprecht J, Freestone M, Pool EJ, Liebenberg RW, Kotze D, van Jaarsveld PP (1999) The effects of B-sitosterol (BSS) and B-sitosterol glucoside (BSSG) mixture on selected immune parameters of marathon runners: inhibition of post marathon immune suppression and inflammation. Int $\mathbf{J}$ Sports Med 20:258-262. PMID:10376483

10. Bouic PJ, Etsebeth S, Liebenberg RW, Albrecht CF, Pegel K, Van Jaarsveld PP (1996) Beta-Sitosterol and beta-sitosterol glucoside stimulate human peripheral blood lymphocyte proliferation: implications for their use as an immunomodulatory vitamin combination. Int J Immunopharmacol 18:693-700. doi:10.1016/ S0192-0561(97)85551-8

11. Choi S, Kim KW, Choi JS, Han ST, Park YI, Lee SK, Kim JS, Chung MH (2002) Angiogenic activity of beta-sitosterol in the ischaemia/reperfusion-damaged brain of Mongolian gerbil. Planta Med 68:330-335. PMID:11988857

12. Chuang CC, Yang RS, Tsai KS, Ho FM, Liu SH (2007) Hyperglycemia enhances adipogenic induction of lipid accumulation: involvement of extracellular signal-regulated protein kinase 1/2, phosphoinositide 3-kinase/Akt, and peroxisome proliferatoractivated receptor gamma signaling. Endocrinol 148:4267-4275. doi:10.1210/en.2007-0179

13. Cornelius P, MacDougald OA, Lane MD (1994) Regulation of adipocyte development. Annu Rev Nutr 14:99-129. doi:10.1146/ annurev.nu.14.070194.000531

14. Devaraj S, Jialal I, Vega-Lopez S (2004) Plant sterol-fortified orange juice effectively lowers cholesterol levels in mildly hypercholesterolemic healthy individuals. Arterioscler Thromb Vasc Biol 24:e25-28. doi:10.1161/01.ATV.0000120784.08823.99

15. Hwang SL, Kim HN, Jung HH, Kim JE, Choi DK, Hur JM, Lee JY, Song H, Song KS, Huh TL (2008) Beneficial effects of beta-sitosterol on glucose and lipid metabolism in L6 myotube cells are mediated by AMP-activated protein kinase. Biochem Biophys Res Commun 377:1253-1258. doi:10.1016/j.bbrc.2008.10.136

16. Imanaka H, Koide H, Shimizu K, Asai T, Kinouchi Shimizu N, Ishikado A, Makino T, Oku N (2008) Chemoprevention of tumor metastasis by liposomal beta-sitosterol intake. Biol Pharm Bull 31:400-404. doi:10.1248/bpb.31.400

17. Ivorra MD, D'Ocon MP, Paya M, Villar A (1988) Antihyperglycemic and insulin-releasing effects of beta-sitosterol 3-beta-Dglucoside and its aglycone, beta-sitosterol. Arch Int Pharmacodyn Ther 296:224-231. PMID:3071280

18. Ivorra MD, Paya M, Villar A (1990) Effect of beta-sitosterol-3beta-D-glucoside on insulin secretion in vivo in diabetic rats and in vitro in isolated rat islets of Langerhans. Pharmazie 45:271-273. PMID:2200064

19. Kandulska K, Nogowski L, Szkudelski T (1999) Effect of some phytoestrogens on metabolism of rat adipocytes. Reprod Nutr Dev 39:497-501. PMID:10493154

20. Kim YK, Choi HY, Kim NH, Lee W, Seo DW, Kang DW, Lee HY, Han JW, Park SW, Kim SN (2007) Reversine stimulates adipocyte differentiation and downregulates Akt and p70(s6 k) signaling pathways in 3T3-L1 cells. Biochem Biophys Res Commun 358:553-558. doi:10.1016/j.bbrc.2007.04.165

21. Le Lay S, Lefrere I, Trautwein C, Dugail I, Krief S (2002) Insulin and sterol-regulatory element-binding protein-1c (SREBP-1C) regulation of gene expression in 3T3-L1 adipocytes. Identification of CCAAT/enhancer-binding protein beta as an SREBP-1C target. J Biol Chem 277:35625-35634. doi:10.1074/jbc.M203913200

22. Lim SL, Chai JW, Kuppusamy UR (2008) Evaluation of Syzygium jambolanum methanolic leaf extract for insulin-like properties. Res J Biol Sci 3:1109-1114. doi:10.3923/rjbsci.2008.1109.1114PDF

23. Livak KJ, Schmittgen TD (2001) Analysis of relative gene expression data using real-time quantitative PCR and the 2(-Delta Delta C(T)) Method. Methods 25:402-408. doi:10.1006/meth.2001.1262

24. Malini T, Vanithakumari G (1990) Rat toxicity studies with betasitosterol. J Ethnopharmacol 28:221-234. doi:10.1016/0378-8741 (90)90032-O

25. Marin P, Hogh-Kristiansen I, Jansson S, Krotkiewski M, Holm G, Bjorntorp P (1992) Uptake of glucose carbon in muscle glycogen and adipose tissue triglycerides in vivo in humans. Am J Physiol 263:E473-480. PMID:1415527

26. Moon DO, Kim MO, Choi YH, Kim GY (2008) Beta-Sitosterol induces $\mathrm{G}(2) / \mathrm{M}$ arrest, endoreduplication, and apoptosis through the Bcl-2 and PI3 K/Akt signaling pathways. Cancer Lett 264:181-191. doi:10.1016/j.canlet.2008.01.032

27. Moon DO, Lee KJ, Choi YH, Kim GY (2007) Beta-sitosterolinduced-apoptosis is mediated by the activation of ERK and the downregulation of Akt in MCA-102 murine fibrosarcoma cells. Int Immunopharmacol 7:1044-1053. doi:10.1016/j.intimp.2007.03.010

28. Moon EJ, Lee YM, Lee OH, Lee MJ, Lee SK, Chung MH, Park YI, Sung CK, Choi JS, Kim KW (1999) A novel angiogenic factor derived from Aloe vera gel: beta-sitosterol, a plant sterol. Angiogenesis 3:117-123. doi:10.1023/A:1009058232389

29. Nestel P, Cehun M, Pomeroy S, Abbey M, Weldon G (2001) Cholesterol-lowering effects of plant sterol esters and nonesterified stanols in margarine, butter and low-fat foods. Eur J Clin Nutr 55:1084-1090. doi:10.1038/sj.ejen.1601264

30. Olefsky JM (1977) Insensitivity of large rat adipocytes to the antilipolytic effects of insulin. J Lipid Res 18:459-464. PMID:894138

31. Pegel KH (1997) The importance of sitosterol and sitosterolin in human and animal nutrition. S Afr J Sci 93:263-268. ISI: A1997YC29400005

32. Sanders DJ, Minter HJ, Howes D, Hepburn PA (2000) The safety evaluation of phytosterol esters. Part 6. The comparative absorption and tissue distribution of phytosterols in the rat. Food Chem Toxicol 38:485-491. doi:10.1016/S0278-6915(00)00021-1 
33. Stryer L (1995) Biochemistry. W. H. Freeman \& Co, New York

34. Sutherland WH, Scott RS, Lintott CJ, Robertson MC, Stapely SA, Cox C (1992) Plasma non-cholesterol sterols in patients with non-insulin dependent diabetes mellitus. Horm Metab Res 24:172-175. PMID:1601392

35. Szkudelska K, Nogowski L, Szkudelski T (2008) Genistein, a plant-derived isoflavone, counteracts the antilipolytic action of insulin in isolated rat adipocytes. J Steroid Biochem Mol Biol 109:108-114. doi:10.1016/j.jsbmb.2007.12.006

36. Thompson GR, Grundy SM (2005) History and development of plant sterol and stanol esters for cholesterol-lowering purposes. Am J Cardiol 96:3-9. doi:10.1016/j.amjcard.2005.03.013
37. Trinder P (1969) Determination of blood glucose using an oxidase-peroxidase system with a non-carcinogenic chromogen. J Clin Pathol 22:158-161. doi:10.1136/jcp.22.2.158

38. Weizel A, Richter WO (1997) Drug therapy of severe hypercholesterolemia. Eur J Med Res 2:265-269. PMID:9182654

39. Wilt TJ, MacDonald R, Ishani A (1999) Beta-sitosterol for the treatment of benign prostatic hyperplasia: a systematic review. BJU Int 83:976-983. doi:10.1046/j.1464-410x.1999.00026.x

40. Yoshida Y, Niki E (2003) Antioxidant effects of phytosterol and its components. J Nutr Sci Vitaminol (Tokyo) 49:277-280. PMID: 14598915 